\title{
5 \\ How do policy professionals in New Zealand use academic research in their work?
}

Karl Löfgren and Sarah Hendrica Bickerton ${ }^{1}$

\section{Introduction}

How do policy professionals in New Zealand use academic sources and find good evidence for their policy analysis and advice to governments and other stakeholders? A few years ago, one of the authors was delivering a methods course for post-experience masters students in public policy at Victoria University of Wellington. The methods presented in the course included classics, such as systematic reviews, cost-benefit analysis and basic statistics, as well as prescriptive ideas around the importance of utilising academic outputs to enhance the quality of policy solutions. While the students valued and appreciated this evidence-based approach to policy using academic research, it seemed like their work practice was not embodied by any systematic and rigorous pursuit of academic evidence. During a discussion session, participants were asked how they normally responded to a call for evidence in practical policymaking situations. The typical response was to 'see what they know, and do, in overseas jurisdictions' (especially in Victoria, New South Wales, the UK and Canada) and 'ascertain if we can copy that'. Although this is just

\footnotetext{
1 The authors wish to thank Building Research Association New Zealand Ltd (BRANZ) for the financial support, and all the respondents that volunteered to be part of the study.
} 
anecdotal evidence, and probably should not be overstated, it nevertheless tells us something about the use of social science research among policy professionals in New Zealand (and probably elsewhere).

In this chapter, we analyse how different policy workers inside and outside government perceive and use different forms of research-based sources. The overarching research question is: how do policy professionals in New Zealand utilise academic outputs? We examine constraining and enabling factors for using research outputs, the accessibility and usefulness of different forms of research sources, and the demand, need and relevance of different forms of research outputs. The results are based on two empirical studies: 1) a survey of New Zealand policy analysts/ advisers working for government conducted in 2015 with 220 valid responses; 2) 15 focus groups held in 2018 with different stakeholders in the housing policy field in New Zealand. These studies show that the ideal of evidence-based policymaking (EBPM) is far from prevalent in day-today policy work; instead, political considerations, crises and 'narratives' guide the operations.

In the next section, we briefly review some of the academic discussion on 'two communities' and the existing body of knowledge relating to practitioner-academic interaction. In Section 3, we present the data and the methods employed for the two empirical studies. Section 4 examines themes identified from the studies. In the final section, we consider what can be achieved to enhance the utilisation of academic outputs in the policy professional communities.

\section{'Two communities'}

The global EBPM movement, with its rational promise of policy decisions based on the best available evidence, has been around since the 1990s and still attracts a large number of proponents (and governments) despite its critics (Kay 2011; see also Cairney 2016; Cairney, Oliver \& Wellstead 2016; Head 2008). In New Zealand, this movement has been institutionalised through the establishment of the Office of the Prime Minister's Chief Science Advisor (PMCSA), which seeks to improve 'the government's ministries and agencies use of evidence in both the formation and evaluation of policy' (PMCSA 2013, p. 3; see also PMCSA 2011). However, despite numerous attempts to achieve a higher degree of evidence-based policy, once we leave the symbolic level and reach the 
'beltway' of policy professionals actually doing policy work, this has proven to be more challenging than anticipated (Colebatch 2006). There appear to be numerous barriers between academics and policy professionals in terms of utility, time horizons, language, communication etc., such that they have been described as belonging to 'two separate communities' (Caplan 1979; Amara, Ouimet \& Landry 2004). According to this representation, academics in their 'ivory towers' can afford to probe into esoteric matters divorced from real world problems (because they enjoy the time and resources), while 'beltway' policy workers are subjected to executive decisions, tight time constraints and electoral cycles (Caplan 1979; see Mercer this volume, Chapter 3).

The 'two communities' metaphor seems to have gained currency among both academics and policy workers over the years; however, its applicability has been questioned on several grounds (Newman 2014; Newman \& Head 2015; Newman, Cherney \& Head 2016). First, technological and digital developments have advanced policy workers' access to academic research findings. In particular, the evolution of information and communication technologies has made it easier and less expensive for policy workers in government to access vast reservoirs of academic knowledge, to identify and make direct contacts with academics, and to review the existing body of academic knowledge, all from their office desks. Although university libraries and academic publishers still do not offer full and free access to all academic publishing, much research of relevance to policy advice is often only a Google search away.

Second, even though several studies empirically confirm the gloomy narrative of 'two communities' (with policy workers not utilising academic research), there are notable individual exceptions. Policy workers do not constitute a homogenous group; they comprise diverse communities (Colebatch 2006). One major distinction that some of the earlier literature on the 'two communities' missed was the difference between those in the policy community acting as 'politicians' (i.e. ultimate 'decision-makers') and those acting as 'bureaucrats' (Newman, Cherney \& Head 2016). Moreover, and to make matters even more complicated, while it is easy to discern these two roles in a theoretical and/or official sense, in practice, they are usually conflated.

Third, some policy domains are, by tradition (or perhaps necessity), more connected to the academic world and disciplinary reasoning than others, and have built both infrastructure and capabilities to tap into the 
abundance of existing knowledge and evidence (e.g. health, economics, the environment and education). Meanwhile, other domains, such as land use, regulatory functions, incarceration or local government, lack this capability for a number of reasons, and remain isolated from academic research. In a similar vein, it should be emphasised that both the original 'two communities' literature, and the more recent debates, have usually focused on social science knowledge rather than a broader understanding of evidential science (Caplan, Morrison \& Stambaugh 1975; Cherney et al. 2013). As pointed out by Wehrens (2014, p. 548), 'the two communities approach overemphasizes both the heterogeneity between domains and the homogeneity within the domains of research and policy'.

Fourth, policy rests on several different components of which evidence or 'knowledge' in the classical analytical sense is just one (Majone 1989). Following Flyvbjerg's (2001) Aristotelian categories of knowledge, Tenbensel (2006) distinguishes between three type of knowledge: 1) episteme - the analytical rational type of knowledge, 2) techne - the practical-technical or 'applied' type of knowledge and 3) phronesisthe value/normative type of knowledge (see also Head 2010; Cairney this volume, Chapter 13). These can be seen both as sources of knowledge production and different forms of demand for types of knowledge. While combinations of all these types of knowledge are essential for producing strong policies, the scientific community is predominantly producing epistemic knowledge, as that is the convention. Consequently, policy workers' demand for knowledge (in the sense of practical skills, experience and normative guidance) also needs to be met from sources other than purely academic ones.

Finally, and as pointed out by some of the critics of the 'two communities' model, while the idea resonates well with the experiences of academics and policy professionals, it fails to adequately explain why problems exist in the relationship (Lin \& Gibson 2003). The premise of 'two communities' is borne by an a priori proposition that it is possible to clearly distinguish policy from academic activities, that power is located in the policy world (with the academic world detached from politics), and that the interface between value laden policy and an 'objective' academic world operates through translation and persuasion (Lin \& Gibson 2003). By contrast, science, technology and society researchers (e.g. Bijker, Bal \& Hendriks 2009; Jasanoff 2013) point to how academic research and policy are co-produced. While evidence-based or scientific knowledge is embedded in all societal institutions, politics and policy equally affect such notions of evidence or knowledge. 


\section{Methodology}

This chapter draws from two empirical studies: the first is based on a quantitative survey and the second on qualitative focus groups. The two studies also differ in terms of scope, with the first seeking to capture the broad community of policy analysts and advisers mainly working inside different government agencies, and the second focusing on the broader community of policy workers both inside and outside government within a specific policy sector (housing).

\section{The survey}

The survey was undertaken online in March and April 2015 using Qualtrics software. The sampling frame was identified with the active support of the Institute for Public Administration New Zealand (IPANZ) and the Public Service Association (PSA) using their membership database to identify relevant respondents. Based on the notion of 'policy workers' (Colebatch 2006) rather than the narrow concept of 'policy analysts', the study sampled members of the two associations with job titles including 'policy' and/or 'researcher' (however, the related title 'business analyst' was excluded). Among those invited to participate, the most frequent job titles were (senior) policy advisers/analysts. In terms of organisations, the study included all New Zealand ministries, statutory Crown entities (excluding secondary schools), Crown research institutions, state-owned enterprises, district health boards and local governments (the two last categories comprised small groups, and the local government memberships almost exclusively included members working for the major local councils). In total, 49 per cent of respondents worked for government departments or Crown entities, with smaller groups working for local and regional governments and others.

The questions asked in the survey replicated an earlier UK study (Talbott \& Talbott 2014) that sought to identify enablers and barriers for utilising academic outputs, useful disciplines and methods, the relevance and usefulness of different academic sources, and the role of academics in policymaking. A total of 383 invitations to participate were sent to members of IPANZ (14 failed recipients) and 998 invitations were sent to PSA members (four failed recipients). In total, 220 valid responses were obtained during the four weeks the survey was up and running, generating a response rate of 16.6 per cent. Although this was a low 
response, one should bear in mind that our total sampling frame captures the views of a large proportion of the total number of policy professionals in New Zealand. This study was originally published in Löfgren and Cavagnoli (2015).

\section{The focus groups}

The views of a small group of organisational representatives in the housing policy sector were surveyed in May-September 2018. The study design was based on a research project commissioned by Building Research Association New Zealand (BRANZ). Based on previous knowledge and external advice from professionals engaged in housing policy (not all of whom were in government), a number of relevant organisations, including local governments, professional and trade associations, and government agencies, were identified. Through personal approaches to individuals with leading roles within the organisations, small groups were set up within the organisations. These became our focus groups. Following initial contacts via email and phone, the team ended up conducting 14 focus groups and a single one-on-one interview. There were between two and seven participants in each focus group ( 45 participants overall) and the conversations normally lasted 45-60 minutes. In most cases, the focus groups were conducted on the premises of the organisations. Despite working for the same organisations, most participants had different educational and professional backgrounds and performed different functions, including policy advice/analysis, engineering, architecture, urban planning and economics. NVivio software was used for the coding phase. Prior to the study, the research team received human ethics approval from their university.

The participants worked for the following organisations:

- Auckland City Council

- Building \& Construction Industry Training Organisation

- Christchurch City Council

- Dunedin City Council

- Earthquake Commission (EQC)

- Energy Efficiency and Conservation Authority (EECA)

- Hamilton City Council

- Housing New Zealand (HNZ) 
- Institute of Architects (IA)

- Institute of Landscape Architects

- Institution of Professional Engineers New Zealand (IPENZ)

- Lower Hutt City Council

- Ministry of Finance

- Ministry of Housing and Urban Development (MHUD)

- New Zealand Construction Industry Council (NZCIC)

- Wellington City Council.

Two factors out of the control of the research team and related to timing affected the results. First, when we conducted our field studies, the government decided to reorganise the housing policy area by removing housing from the Ministry of Business, Innovation and Employment and relocating the policy sector to a new ministry, MHUD. We managed to get an interview with representatives from MHUD much later, but not in time to include their views in this chapter. Second, our study coincided with the government science advisor's report in June 2018 that found there was no health danger to humans residing in houses in which the narcotic substance methamphetamine had been consumed, but not manufactured-the so-called 'meth myth' report (PMCSA 2018). The previous health recommendation had prescribed that any indoor consumption of methamphetamine would render the dwelling uninhabitable; this had resulted in forced evictions from a number of HNZ properties. Consequently, questions around the utilisation of academic research by people working with housing policy was slightly sensitive. The original qualitative study was published in an internal report (Löfgren \& Bickerton 2019).

\section{Themes}

Three themes from the 2015 survey and 2018 qualitative focus group study provide insight into how policy professionals in New Zealand utilise academic outputs:

- use and usefulness of academic outputs

- enabling and constraining factors

- the role of academic outputs in policy. 
Whereas the survey and the focus groups were similar with respect to the overall objectives and (subsequently) themes, the actual design differed between the two studies. The survey operated with predefined options for answers; although there were open-ended alternatives, the questions were funnelled down to specific responses. Conversely, the qualitative focus groups/interviews allowed the respondents to make sense of the themes in their own way and converse around concepts (such as policy work, knowledge, usefulness etc.) based on their own experiences and practice. This is in contrast to predefined alternatives based on an academic approach to both the research-policy relationship and the linear and stagist policy models.

\section{Understanding the practitioner perspective}

\section{Use and usefulness}

One of the first questions in our 2015 survey sought to determine the extent to which respondents felt that academic outputs were important sources of evidence in their policy work. Perhaps unsurprisingly, the vast majority felt that academic outputs were an important source (41 per cent to a large extent and 57 per cent to some extent). We asked about the sources of academic outputs (Figure 5.1) and, not surprisingly, articles, books, lectures and personal contacts scored highest. That articles in peer-reviewed journals ranked the highest is interesting given that we had anecdotal evidence suggesting that there were obstacles to accessing these. We also asked respondents what kind of disciplinary academic outputs they made use of (see Figure 5.2).

One response in Figure 5.1 that is worth further exploration is 'other websites' and 'other forms of social media'. This category includes co-produced sources such as Wikipedia. Several of the respondents indicated other sources. However, the vast majority of these sources are clearly not academic, but 'grey literature' from governments, think tanks and internal library collections. 


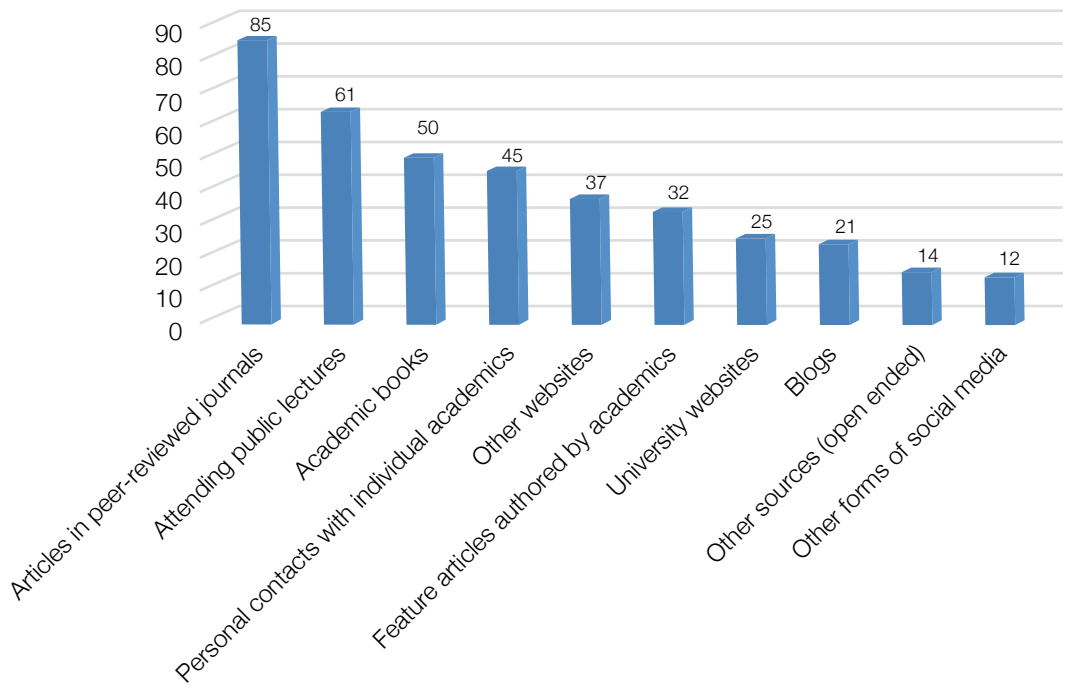

Figure 5.1. Sources of academic outputs (\%).

There were several options available for some of the survey questions, including several possible options for Figure 5.1.

A second set of questions sought to establish which disciplines and methods were considered to be useful in respondents' daily policy work (see Figure 5.2). That the output of traditional social science disciplines (e.g. economics, political science/public policy, statistics and demography) should be at the top, followed by sector specific disciplines (e.g. education and health) was something we anticipated. It should also be mentioned that among 'others' we found several open-ended responses listing disciplines such as 'law', 'history' and 'environmental sciences'. We were not completely sure whether those who registered 'law' as an open-ended answer were referring to actual academic legal research, or whether they just listed law as a prerequisite for policymaking.

Our survey respondents, when prompted to discuss qualitatively what sources they used for gathering research and evidence around their policy work, almost universally described academic research (or that which was perceived as academic) as research that was 'separate' from their policy work. While there were exceptions to this (notably those who worked in areas of regulatory assessment or the more technical foci), academic (or, rather, 'university') research was deemed less useful to respondents, for a variety of reasons. 


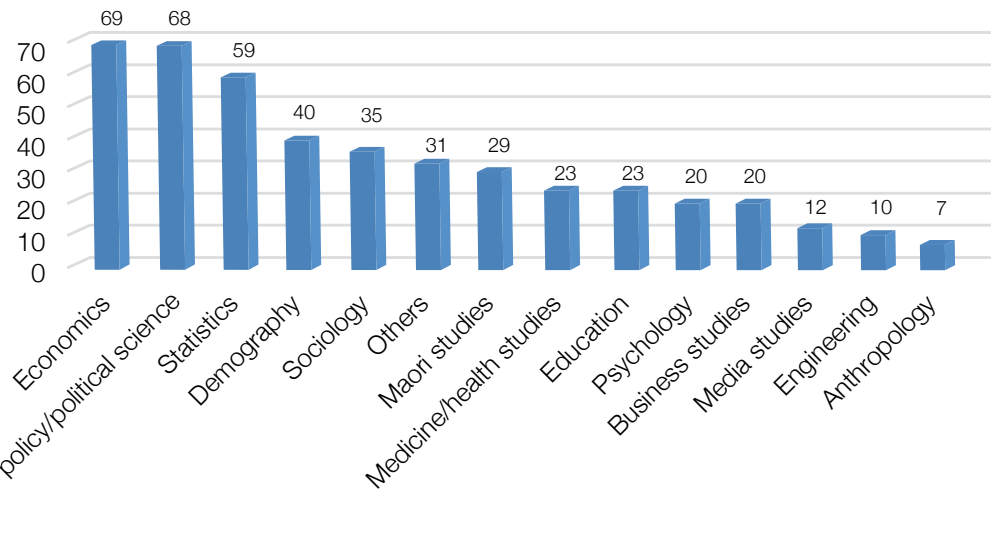

Figure 5.2. Useful academic disciplines in daily work (\%).

More than one answer possible.

We asked the same question of our focus groups and, while there were some areas of overlap, their voices nuanced the overall picture slightly. In terms of useful sources of knowledge, the overwhelming leader was Google Scholar. It was considered a key go-to simply because of its lack of a paywall. While some of the articles Google Scholar highlighted were behind paywalls, the benefit of being able to search and read abstracts gave respondents access to a far wider pool of research than normal.

Another preference among focus group respondents was attendance at conferences and public lectures. Their reasoning was that research presentations were often short, digestible and engaging, while discussions with presenters could increase relevancy and connect to wider policy issues. Further, conferences allowed networking and personal connections to be formed, in addition to research being discussed, which respondents found to be particularly useful.

Respondents also valued peer-to-peer networks. These networks could involve members within similar organisations (such as city councils) or external organisations. Another possibility for these informal networks involved contacting academics directly for copies of their research. If an article or articles were identified behind paywalls as being relevant, respondents would contact that academic directly to see if they could get a copy of the article:

If there's someone's research that I've read who's overseas, I will just email them, say this was really good, can you tell me a bit more about it, is there anything more along these lines you know. (Auckland City Council) 
Other sources included clearing houses that provided annotated bibliographies of recent research, as this fitted with respondents' lack of time for research. Respondents also listed organisations such as BRANZ, the New Zealand Green Building Council, EECA and other professional organisations as sources of both research and information on research done elsewhere. A few of respondents had access to their own libraries and/or research staff/librarians, and some commissioned their own research. Generally, the larger the organisation (e.g. Auckland City Council and Treasury), the more likely it was to have its own library and/ or commission research.

In terms of sources not found to be particularly useful by respondents, the generic category 'universities' was identified. This does not include individual academics (who were seen as quite responsive), but rather academic institutions and their communication channels such as websites or social media platforms. Universities were perceived as mainly pursuing their own goals-goals that did not fit well with what was needed by policymakers.

\section{Enabling and constraining factors}

The enabling and constraining factor of utilising academic outputs mirrored the results in the quantitative survey results. While policy workers made use of academic outputs, many did so infrequently. Questions regarding the enabling and constraining factors for using arguments from academic publications were also asked (Figure 5.3).

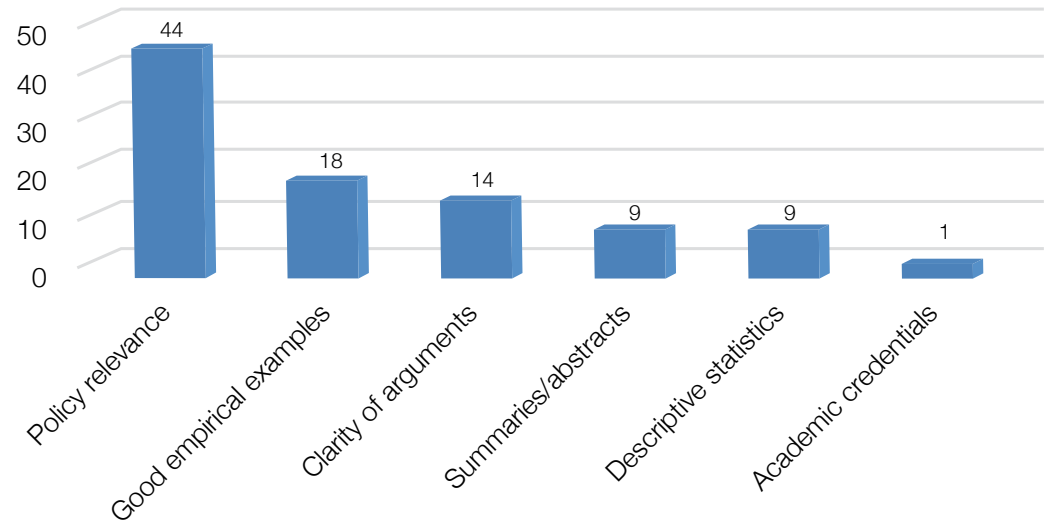

Figure 5.3. Enabling factors (\%).

One alternative. 


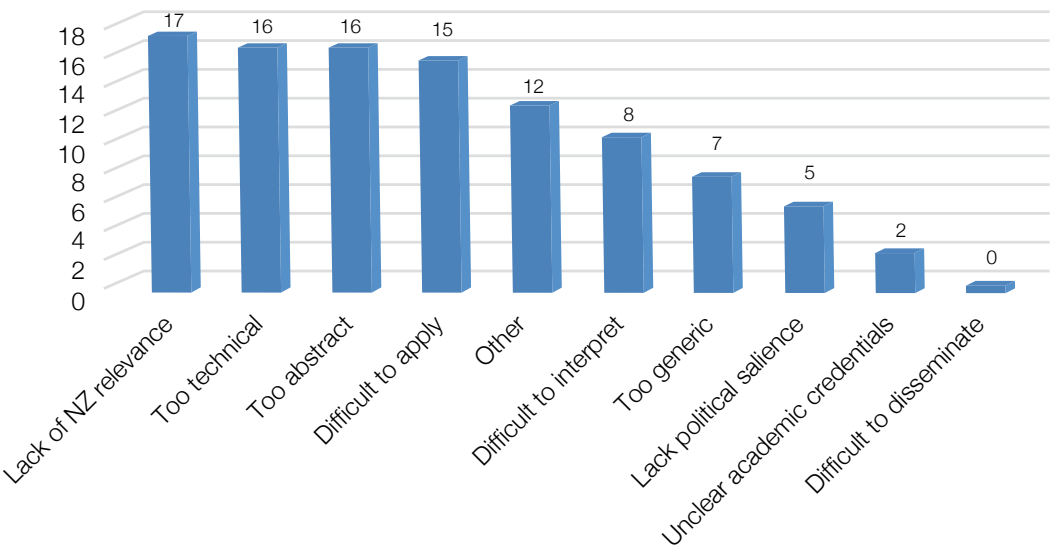

Figure 5.4. Constraining factors for using academic arguments (\%).

It is perhaps not surprising that 'policy relevance', 'good empirical examples' and 'clarity of arguments' represent the answers with the highest number of respondents. However, that 'academic credentials' plays almost no role is perhaps something worth further investigation. The question regarding constraining factors for using academic arguments shows a less clear-cut result (Figure 5.4).

While 'lack of relevance' seems to represent the largest proportion of survey answers, arguments based on the 'two community' metaphor (i.e. too abstract, technical and difficult to apply) seem to be an important theme.

The voices from the qualitative focus groups provided similar responses. Much of the conversations revolved around access in various forms. The format and language of academic outputs was something that all the groups mentioned. Concise summaries and abstracts were highly appreciated for professionals not having the time to read lengthy research studies. Equally, the language used in academic journals was often seen as inaccessible and lacking in applicability to the policymaking process:

I have never read anything like this in my life; it was so weird. Thankfully our academic partners could translate it to us, because we were going- 'what is this?' (IA) 
However, access was also considered a barrier in a more traditional sense. Academic journals behind paywalls were considered a severe impediment to accessing research, with many respondents just giving up on accessing journals as their organisation could not afford to pay for journal database use:

I think there is an inherent contradiction at the heart of academia, whereas you want to publish in a journal, but then people are not allowed to read them unless they purchase at a relatively high cost. (IPENZ)

One group of respondents who found journals useful were policymakers interested in highly technical details; they tended to skim read articles, determining the rigour of the research based on the methodology and references.

A different, broader, theme is the importance of contextual relevance and compatibility. The issue of relevance can become a barrier for using research in many different forms. The first, and perhaps most understandable, issue is whether the research output is relevant for 'my organisation' (i.e. the individual stakeholder). The challenges that different respondents faced are localised specificities that differ in character. For example:

I guess the advantage of something like that [research] is that we have a particular issue and it is in Wellington and it is now, whereas the research that might have gone on might be in Edinburgh in 2013. (Housing policy team in Wellington City Council)

You really need to live in New Zealand to understand the intricacies. (EECA)

Academics and policy workers in the housing policy community are typically working within separate time frames. Whereas the practitioners are seeking solutions to their imminent problems and have to comply with budget and electoral cycles, academics are following their separate systems of funding and reporting mechanisms. As one respondent described it, academic outputs often reflect a single observational point in time, mainly because of funding opportunities and academic fashion:

I find the academic stuff tends to, you know it just has a longer time frame, and tends not to touch on the issues that directly affect our businesses. (NZCIC) 
However, it is worth mentioning that a few of the respondents stated that the academic world should not be blamed for the incompatible time periods. They felt that such challenges were also and equally caused by policy cycles. Moreover, good research is time-consuming:

So, the policy framework is far too short term and reactive and so I wouldn't even say it is the research time frame that needs to shift, it is actually the policy time frame that needs to get real. (IPENZ)

\section{The role of academic outputs in policy}

One of the chief themes in the quantitative survey concerned the views of policy workers regarding the underlying conditions of using academic outputs, and whether academics should be more active. We asked respondents to rate the importance of academic outputs and general academic expertise to their work on a five-graded Likert scale. The mean value for contribution through outputs was 2.73 and for contribution through general academic expertise was 2.90. Yet, we may conclude that the role of the academic as an (available) expert is perceived as more important than their publications. Questions about the work environment's attitude to using academic outputs produced less encouraging results. Asked about whether public sector managers were encouraging the use of academic support on a five-graded Likert scale, the mean was $2.75(\mathrm{n}=161)$. Although the evidence is not especially compelling, it nevertheless provides an indication that 'management' is not overwhelmingly supportive of using academic outputs and may in fact be directly negative. When asked whether there were other requirements (legal, terms of references instructions etc.), the support for using academic outputs was even less. The mean value on a five-graded Likert scale was $2.15(\mathrm{n}=161)$. This suggests that institutional support for using academic outputs among policy workers is not prodigious.

Other questions dealt with the involvement of academics in policy work. An overwhelming majority of respondents ( 80 per cent) responded positively to academics being active in policymaking. However, when asked at what stage academics should be involved, the answers were more varied (see Figure 5.5). 


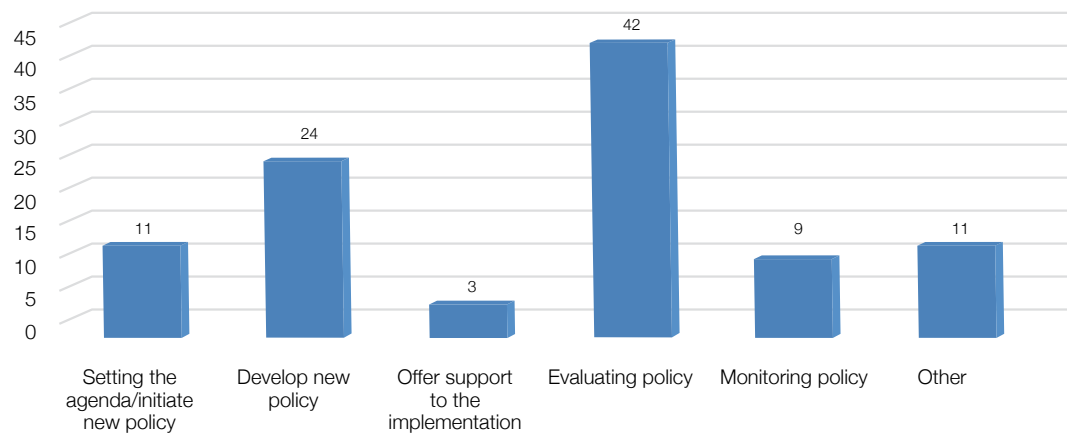

Figure 5.5. 'At what stage in the policy process should academics get involved?' (\%).

The assigned role of 'evaluator' is an interesting finding. One possible interpretation is that academics are conceived as neutral and non-biased in the political game, and therefore represent an obvious choice for appraising outputs and outcomes of policy. Equally, the low indication for academics taking part in the implementation process could probably be an indication of distrust in the managerial skills of academics. The category 'other' was full of qualitative responses that not only criticised the underlying premise of the question (i.e. that the policy process could be divided into discrete stages), but also addressed the need for impartial advice. In addition to asking respondents about the role of academics, we also asked them about their general appreciation of the most important 'informers of policy expertise' (Figure 5.6).

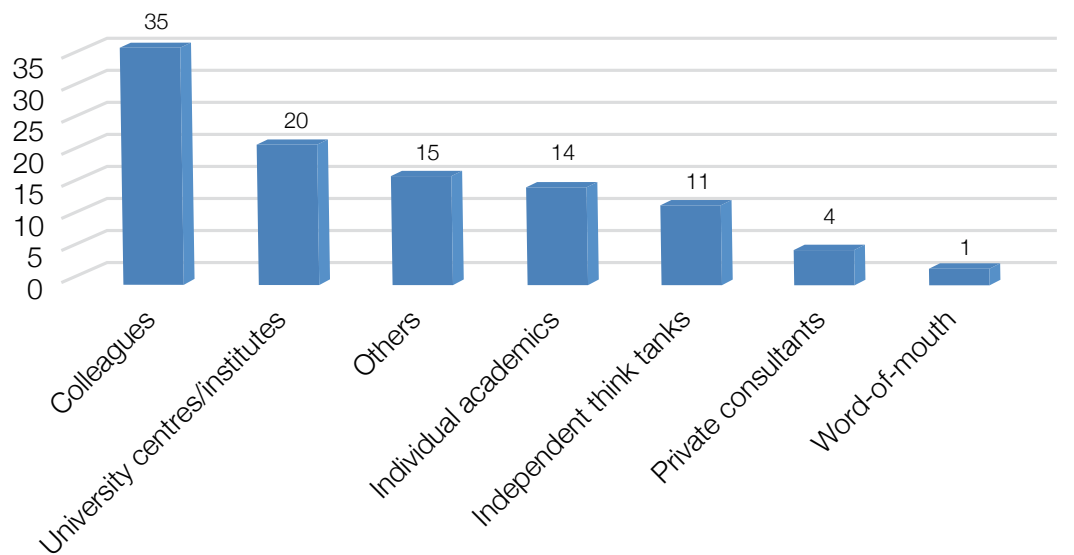

Figure 5.6. Perceptions on the most important informers of policy expertise (\%). 
Unsurprisingly, most respondents turned to their colleagues when they needed policy advice. University centres or specific university institutes were second best on the list of 'good informers'. Less preferred were private consultants who were not considered to be good informers. The broad category 'others' comprised an interesting mix of informers including 'sector', 'stakeholders', 'ministers' and 'departmental experts'. Some respondents stressed that sources of 'policy expertise' needed to understand the policy process (in which their colleagues were usually most important) and policy content (in which academics were seen as the most important informers).

In conjunction with this question, we also asked respondents about what prevented them from using academic outputs.

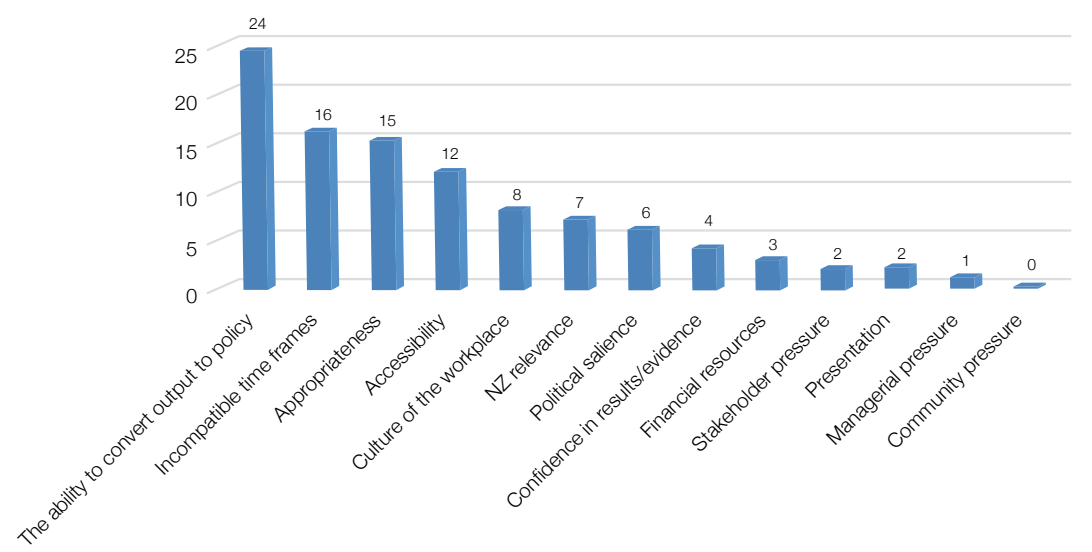

Figure 5.7. 'What prevents you from using academic outputs?'(\%).

Our survey data showed that the main problem appeared to be the two different communities of academia and policy workers. Still, it is somewhat disconcerting that 8 per cent of respondents mentioned the culture of their workplace as a reason not to use academic outputs.

Turning to the qualitative study, we asked the focus groups to discuss their specific needs and demands. The biggest driver of demand was research that was holistic. By this, respondents meant research that was interdisciplinary: 'Yeah, housing is just so multidisciplinary' (Ministry of Finance). This involved such things as intersections of the social aspects of housing, such as affordability, or the mixed nature of communities, or how transport intersects with housing: 
So there's a whole lot of literature on the way in which gentrification actually impacts, not in a positive way in particular existing communities, and there's a whole body of literature internationally on that, but then there's all this other literature on why you want to do economic development, or development in a particular way. But the more you need to ensure that there's quality intensification, you need to ensure the normal standards, and you want to think about affordable housing, and you know we provide advice on a whole range of things and so, if it's so isolated that it's very theoretical, then you know sometimes it doesn't then translate into, so yeah I guess the answer would be yes, that around a range of housing topics, or areas if you can't really apply it, or if it's not the reality. (Auckland City Council)

Some found housing research isolated from this context to be less than desirable:

They're going to give me the sort of the heart and the head. Not just the facts, but also the emotion and the impact, the 'so what?' factor, you know, and ... look at the number of people that are being injured or hurt or the disadvantaged or, equally, in the personal stories through the way our urban form influences people. (Christchurch City Council)

A related response was that policymakers want research that tells a policy 'story' or, as one respondent explained, can 'take the public with you'. This means not merely reporting the facts, but also explaining why the research and results are relevant, how they fit with other pieces of research, how they fit with wider policy narratives and why they might be important to the public:

I think another big thing is also storytelling. Everyone is doing it; I know it is a bit yawny. But you know, it's translating the complex into a story. (EQC)

The policymaker's work is not just the crafting and implementation of policy, but also presenting the policy to the public-justifying or making a case for it. Having researchers that understand that drive and know the import of their research to the wider policy/political world is important and, ultimately, very helpful to policymakers. Conversely, being unaware of the impact of one's research-not knowing or anticipating the problems that releasing it might cause, or leaving it up to others to craft the narrative around such problems_-was seen as damaging to the work of policymakers. 
Our respondents felt that more research was needed on monitoring and evaluating policy initiatives. Once a piece of housing policy was implemented, there was often insufficient monitoring to ensure it achieved its intended goals. Nor was research usually undertaken to evaluate the application of research to assess if it was correctly applied over the long-term:

And we have really very little way of actually monitoring how effective we are in doing that, apart from, you know, the usual statistics, which don't actually give us the detailed level that we need to understand what we're actually doing it. (Christchurch City Council)

In fact, long-term longitudinal research was also found to be lacking in the New Zealand context. Understanding housing and communities over longer periods and over multiple indices was seen as crucial for good housing policy planning, not least because housing planning could be better informed with such research:

Then also the consistency in that sort of longitudinal study that we really had very little of ... which was the point I said to [name] before, that often the academic outputs are a point in time. Yeah. When the research project has funding. It is really important that we have those longitudinal trend data supporting policy decisionmaking as well. And so how we balance point in time with trendtype academia. (Christchurch City Council)

Given that the consistent refrain from all our respondents was that attempting to find time to access and review research in their fields was important but difficult, it is not surprising that one of the major desires from respondents was some form of annotated research digest:

The fact that the construction industry is so busy, they haven't got time to understand what the latest research is and can't incorporate it into their practice because, and this is where it's almost like the clearing house, it needs somebody to be working full time to say 'well that's a bit academic, but that's actually really useful, and that could really help your business'. (EQC)

Effectively, research digests would serve as replacements for the research units that used to be part of many organisations, while also freeing up policy practitioners' time. Research digests would allow policy practitioners to spend time reading appropriate texts, rather than trying to find them. Being responsive, with quick turnarounds, to literature requests would continue this knowledge-broker function. 


\section{Concluding remarks}

With the necessary caveats about generalising from two smallish samples across the public sector, we think it is safe to suggest a few propositions regarding New Zealand policy workers' utilisation of academic outputs.

First, while it is difficult to avoid the metaphor of 'two communities', there is good reason not to exaggerate the gaps between academia and the policy world. Despite some of the strong voices expressed here, academic outputs were being utilised by policy professionals and there were institutionalised channels for communication. Moreover, if one takes a wider look, these findings resonate well with the findings of similar international studies of the policy sector in terms of culture, 'language', time frames, rigour and incentives (Talbot \& Talbot 2014; Oliver et al. 2014; Cairney 2016; see also Cairney this volume, Chapter 13). Having said that, the two New Zealand studies presented here, and the differences between the findings, also reflect research from Australia where organisational factors do play an important role (Head et al. 2014). While the survey respondents mainly had specialised and professional policy analyst/advisory functions in government organisations, and thus were more inclined to use academic outputs, the 'jack-of-all-trades' professionals within housing policy approached academic research differently.

Second, access to peer-reviewed material in the form of academic journal articles appeared to be unevenly distributed. While most of the survey respondents had access to digital databases of academic journals, those working for professional associations, local governments and others were generally locked out from this type of material. Several respondents mentioned problems of timeliness, policy relevance and reader accessibility as constraining factors for using academic outputs.

Third, in terms of usefulness, we may construe that, in addition to identifying relevant disciplines and methods based in the individual policy sector, there are concerns around the applicability of international research findings in a New Zealand and/or local context. It is also noteworthy that one of the more appreciated methods for identifying relevant academic outputs was to use digital search engines such as Google, whereas universities' specially designated external engagement and research entry points were not considered especially useful. 
Finally, we must conclude that, although there were signs of an active use of academic outputs within the community of policy workers, there were equally signs endorsing the metaphor of 'two distinct communities'. Yet, we must conclude that the vast majority of respondents did make some use of academic outputs and most appreciated peer-reviewed academic sources. This demonstrates that the connection between the professor and the policy worker is probably more complex than we assume, thereby highlighting the need for further research.

\section{References}

Amara, N, Ouimet, M \& Landry, R 2004, 'New evidence on instrumental, conceptual and symbolic utilisation of university research in government agencies', Science Communication, vol. 26, no. 1, pp. 75-106, doi.org/10.1177/ 1075547004267491.

Bijker WE, Bal, R \& Hendriks, R 2009, The paradox of scientific authority: The role of scientific advice in democracies, MIT Press, Cambridge, MA.

Cairney, P 2016, The politics of evidence-based policy-making. Palgrave Pivot, London, UK, doi.org/10.1057/978-1-137-51781-4.

Cairney, P, Oliver, K \& Wellstead, A 2016, 'To bridge the divide between evidence and policy: Reduce ambiguity as much as uncertainty', Public Administration Review, vol. 76, no. 3, pp. 399-402, doi.org/10.1111/puar.12555.

Caplan, N 1979, 'The two-communities theory and knowledge utilization', American Behavioral Scientist, vol. 22, no. 3, pp. 459-70.

Caplan, N, Morrison, A \& Stambaugh, R 1975, The use of social science knowledge in policy decisions at the national level, Institute for Social Research, Ann Arbor, MI, doi.org/10.1177/000276427902200308.

Cherney, A, Head, B, Boreham, P, Povey, J \& Ferguson, M 2013, 'Research utilization in the social sciences: A comparison of five academic disciplines in Australia', Science Communication, vol. 35, no. 6, pp. 780-809, doi.org/ $10.1177 / 1075547013491398$.

Colebatch, HK 2006, 'What work makes policy?', Policy Sciences, vol. 39, no. 4, pp. 309-21, doi.org/10.1007/s11077-006-9025-4.

Flyvbjerg, B 2001, Making social science matter: Why social inquiry fails and how it can succeed again, Cambridge University Press, Cambridge, UK, doi.org/ 10.1017/CBO9780511810503. 
Head, B 2008, 'Three lenses of evidence-based policy', Australian Journal of Public Administration, vol. 67, no. 1, pp. 1-11, doi.org/10.1111/j.1467-8500.2007. 00564.x.

Head, B 2010, 'Reconsidering evidence-based policy: Key issues and challenges', Policy and Society, vol. 29, no. 2, pp. 77-94, doi.org/10.1016/j.polsoc. 2010.03.001.

Head, B, Ferguson, M, Cherney, A \& Boreham, P 2014, 'Are policy-makers interested in social research? Exploring the sources and uses of valued information among public servants in Australia', Policy and Society, vol. 33, pp. 89-101, doi.org/10.1016/j.polsoc.2014.04.004.

Jasanoff, S 2013, States of knowledge: The co-production of science and the social order, Routledge, London, UK.

Kay, A 2011, 'Evidence-based policy-making: The elusive search for rational public administration', Australian Journal of Public Administration, vol. 70, no. 3, pp. 236-45, doi.org/10.1111/j.1467-8500.2011.00728.x.

Lin, V \& Gibson, B (eds) (2003), Evidence-based health policy: Problems and possibilities, Oxford University Press, Melbourne, Vic.

Löfgren, K \& Bickerton, S 2019, Use of academic research and other sources of knowledge in New Zealand housing policy, BRANZ Study Report SR416, Judgeford, NZ.

Löfgren, K \& Cavagnoli, D 2015, 'The policy worker and the professorunderstanding how New Zealand policy workers utilise academic research', Policy Quarterly, vol. 11, no. 3, pp. 64-72. (Subsequently reprinted in New Zealand Science Review, vol. 72, no. 3, pp. 67-74, doi.org/10.26686/ pq.v11i3.4546.)

Majone, G 1989, Evidence, argument and persuasion in the policy process, Oxford University Press, Oxford, UK.

Newman, J 2014, 'Revisiting the "two communities" metaphor of research utilisation', International Journal of Public Sector Management, vol. 27, no. 7, pp. 614-27, doi.org/10.1108/IJPSM-04-2014-0056.

Newman, J, Cherney, A \& Head, BW 2016, 'Do policymakers use academic research? Reexamining the "two communities" theory of research utilization', Public Administration Review, vol. 76, no. 1, 24-32, doi.org/10.1111/ puar. 12464 . 
Newman, J \& Head, BW 2015, 'Beyond the two communities: A reply to Mead's "why governments often ignores research", Policy Sciences, vol. 48, no. 3, pp. 383-93, doi.org/10.1007/s11077-015-9226-9.

Office of the Prime Minister's Chief Science Advisor (PMCSA) 2011, 'Towards better use of evidence in policy formation', Discussion paper, PMSA, Wellington, NZ.

Office of the Prime Minister's Chief Science Advisor (PMCSA) 2013, The role of evidence in policy formation and implementation, PMSA, Wellington, NZ.

Office of the Prime Minister's Chief Science Advisor (PMCSA) 2018, Methamphetamine contamination in residential properties: Exposures, risk levels, and interpretation of standards, PMSA, Wellington, NZ.

Oliver, K, Innvaer, S, Lorenc, T, Woodman, J \& Thomas, J 2014, 'A systematic review of barriers to and facilitators of the use of evidence by policymakers', BMC Health Service Research, vol. 14, p. 2, doi.org/10.1186/1472-6963-14-2.

Talbot, C \& Talbot, C 2014, 'Sir Humphrey and the professors: What does Whitehall want from academics? A survey of senior civil servants' views on the accessibility and utility of academic research and expertise', Working paper, Policy@Manchester, Manchester University.

Tenbensel, T 2006, 'Policy knowledge for policy work', in HK Colebatch (ed.), The work of policy: An international survey, Lexington Books, Latham, MD.

Wehrens, R 2014, 'Beyond two communities-from research utilization and knowledge translation to co-production?', Public Health, vol. 128, no. 6, pp. 545-51, doi.org/10.1016/j.puhe.2014.02.004. 
This text is taken from Learning Policy, Doing Policy: Interactions Between Public Policy Theory, Practice and Teaching, edited by Trish Mercer, Russell Ayres, Brian Head and John Wanna, published 2021 by ANU Press, The Australian National University, Canberra, Australia.

$$
\text { doi.org/10.22459/LPDP.2021.05 }
$$

